\title{
Küresel Atmosferik Salınımların Büyük Menderes ve Gediz Akarsularının Akımları Üzerindeki Etkisi
}

\author{
Emre Kebapcıoğlu' ${ }^{1}$, Turgay Partal ${ }^{1, *}$ \\ ${ }^{1}$ Ondokuz Mayıs Üniversitesi, Mühendislik Fakültesi, Inşaat Mühendisliği, 55139, Samsun.
}

\section{Özet}

Son zamanlarda yapılan çalıșmalar küresel atmosferik salınımların iklim parametreleri üzerinde etkili olduğunu göstermektedir. Bu çalışma, Kuzey Atlantik Salınımı (NAO), Arktik Salınım (AO) ve Güneyli Salınımı (SO) gibi küresel atmosferik salınımları ile Büyük Menderes ve Gediz akımları arasındaki ilișkinin belirlenmesi için yapılmıștır. Büyük Menderes ve Gediz havzalarında bulunan 19702015 yılları arasındaki 45 yıllık dönemde ölçümleri Devlet Su Işsleri (DSİ) tarafindan yapılan 5 akım istasyonundaki yıllık ve mevsimlik ortalama akımlar incelenmiştir. Daha sonra, NAO, AO ve SO indeksleri ile yıllık ve mevsimsel akımlar arasındaki ilişki korelasyon analizi ile belirlenmiştir. Ayrıca, istenilen sayıda periyodik bileşenler elde edebilmek için orijinal akım verileri ayrı dalgacık dönüşümü ile bileşenlerine ayrlmıştır. Bulunan dalgacık bileşenleri (D1, D2, D3, D4 ve A) ile atmosferik indeksler arasındaki korelasyonlar incelenmiştir. Sonuç olarak, akımlar ile AO/NAO indeksleri arasında yıllık, kış ve ilkbahar periyotlarında güçlü bir negatif korelasyon vardır. Ayrıca dalgacık periyodik bileşenleri, küresel atmosferik salınımların akım verileri ile ilişkisinin temel faktörlerini göstermiştir.

\section{$\underline{\text { Anahtar Sözcükler }}$}

Kuzey Atlantik Salınımı, Arktik Salınım, Güneyli Salınımı, Dalgacık Analizi, Akım

\section{The Impacts of Global Atmospheric Oscillations on Büyük Menderes and Gediz Streamflows}

\begin{abstract}
Recent studies show that global atmospheric circulations are efficient on climate parameters. This study has been carried out to analyze the relationship between the streamflow data in Büyük Menderes/Gediz Basin and the global atmospheric oscillations such as the Southern Oscillation (SO), the North Atlantic Oscillation (NAO) and the Arctic Oscillation (AO). The average annual and seasonal flows at the current 5 stations located in Büyük Menderes basin and Gediz basin, whose measurements were made by the DSI in the 45 year period between 1970 and 2015 have been studied. Then, the relationship between NAO, AO, SO indices and streamflows was determined by correlation analysis. In addition, in order to obtain the periodic components, the original observed data were separated into their components by discrete wavelet transform. The correlations between the found wavelet components $(D 1, D 2, D 3, D 4$ and A) and atmospheric indices were examined. As a result, this study found that there is a strong negative correlation between the streamflow and the AO/NAO indices at the annual/winter and spring period. Moreover, the wavelet periodic components showed to the main factors for the relationship of the streamflow data with the global atmospheric patterns.
\end{abstract}

$\underline{\text { Keywords }}$

North Atlantic Oscillation, Arctic Oscillation, Southern Oscillation, Wavelet Analysis, Streamflow

\section{Giriş}

İklim değişikliği ve kuraklık gibi küresel sorunların belirtilerini yansıtan en önemli değişkenlerden biri akarsu akımlarıdır. Bunun yanında akarsu akımlarındaki değişimler baraj haznelerinin planlanması ve taşkın kontrolü gibi su kaynakları konularında en önemli değişkenlerin başında gelmektedir. Bu sebeple akarsuların geçmiş akım verilerinin analizi her zaman önemli bir konu olmuştur.

Akarsu akım verileri hidrolojik döngünün ana unsurlarından biridir. Hidrolojik döngüdeki değişikler önemli ölçüde su kaynaklarının kalitesini ve miktarını etkiler. Ayrıca hidrolojik döngüdeki değişikler küresel iklim değiş̧ikliğinin önemli sonuçlarından biri kabul edilmiştir (Durdu 2010). İklim değişikliği ile hidrolojik değişkenler arasındaki ilişkiyi anlamaya yönelik çalışmalar iklim parametreleri ve atmosferik indeksler arasındaki korelasyonları bulmaya odaklanmıştır. Bu hidrolojik süreçlerin davranışlarının analizi için çok etkili bir yöntemdir (Tamaddun vd. 2016). Önceki çalışmalar, akım değişkenliğinin büyük ölçekli atmosferik salınımlarla ilişkili olduğunu göstermiştir (Dettinger ve Diaz 2000; Sagarika vd. 2015). 
Kuzey Atlantik Salınımı (NAO) ve El Nino Güneyli Salınım (ENSO) gibi atmosferik salınımların, Avrupa Bölgesi boyunca hidrolojik döngünün değişkenliğini etkilediği bulunmuştur (Polonsky vd. 2007; Burt ve Howden 2013; Fedekova vd. 2014; Philandras vd. 2015; Ward vd. 2016; Iqbal vd. 2016). Bu çalışmaların sonucu olarak Akdeniz-Karadeniz havzalarındaki analizlerde yıllar arasındaki değişkenliğin NAO ve ENSO ile bağlantılı olduğu tespit edilmiştir (Voskresenskaya ve Maslova, 2011). Yapılan önceki çalışmalar, kış mevsiminde NAO’nun negatif olduğu dönemlerde, Kuzey Avrupa'da daha kurak ve Akdeniz'de daha yağışlı iklim koşulları meydana geldiğini göstermektedir (Sezen ve Partal 2019).

Türkiye'de atmosferik salınımlar ile hidrolojik değişkenler arasındaki ilişkiler üzerine son yirmi yılda çok sayıda çalışma yapılmıştır (Düzenli vd. 2018). Karabörk vd. (2005), Türkiye yağış/akış verileri ile NAO arasında bazı bağlantılar olduğunu göstermiştir. Kahya ve Karabörk (2001), Türkiye'nin Batı Karadeniz bölgesindeki akarsu akımlarının ENSO'nun ekstrem fazlarıyla ilişkili olduğunu göstermiştir. Sezen ve Partal (2019), Türkiye'deki sıcaklık verileri ile Kuzey Denizi Hazer Paterni (NCP) ve Arktik salınım (AO) arasında yüksek negatif korelasyon katsayılarının gözlendiğini göstermiştir. Kutiel ve Türkeş (2005), NCP'nin negatif fazında Türkiye'nin iç bölgelerinde hava sıcaklıklarının daha sıcak, NCP'nin pozitif fazında ise hava sıcaklıklarının daha düşük olduğunu göstermiştir. Vazifehkhah ve Kahya (2018), Türkiye'deki akımların, standartlaştırılmış akım indekslerini kullanarak NAO ve AO aşırı fazlarının etkilerini incelemiştir. Yaptıkları çalışmada kış ve sonbaharda NAO ve AO'nun aşırı değerleri ile Türkiye genelinde meydana gelen kısa dönem kuraklıklar arasında bir ilişki bulmuşlardır. Yılmaz vd. (2020) Karadeniz bölgesi yağışlarının NAO ile ilişkisini trend analizi ve korelasyon analizi ile incelemişler ve zayıfta olsa bir ilişki tespit etmişlerdir.

Dalgacık analizi, hidroloji ve iklimsel zaman serisi analizlerinde son yıllarda kullanılan faydalı bir yöntemdir (Pisoft vd. 2004; Partal 2012; Nalley vd. 2012; Adarsh ve Reddy 2015; Adamovski and Prokoph 2014). Dalgacık analizinin avantajı, hem zaman hem periyot ortamında kararsız verilerin incelenmesini mümkün kılmasıdır. Bu sebeple dalgacık dönüşümü, küresel indeksler ile hidro-klimatolojik değişkenler arasındaki ilişkiyi tanımlamak için kullanışlı bir yöntemdir (Jiang vd. 2014). Sezen ve Partal (2019), dalgacık tabanlı analiz kullanarak Türkiye'de Karadeniz Bölgesi’nin NCP/NAO ve yağış/sıcaklık verileri arasındaki ilişkileri araştırmıştır. Özellikle kış mevsiminde güçlü bir ilişki bulmuşlardır.

Son yıllarda yapılan çalışmaların çoğu NAO ve SO gibi atmosferik salınımlar ile Türkiye yağış ve sıcaklık verileri arasındaki ilişkileri belirlemeye yöneliktir. AO’nun Türkiye akarsularının akım verileri üzerindeki etkileri üzerine birkaç çalışma yapılmıştır (Vazifehkhah ve Kahya 2018). Ayrıca Türkiye akarsularının akım verilerinin mekânsal ve zamansal özelliklerini ele alan dalgacık tabanlı analizlerin kullanıldığı detaylı bir çalışma henüz yapılmamıştır. Su kaynaklarının sürdürülebilir olması için akarsulardaki akım özelliklerinin belirlenebilmesi oldukça önemlidir. Bu iki havza 25000 km²‘lik drenaj alanı ile Ege Bölgesi’nin en büyük iki havzasıdır. Ayrıca küresel iklim değişikliğinin yağışlar üzerindeki etkileri ve artan su talepleri nedeniyle bölgenin akımlarının iyi analiz edilmesi gerekir. Bu amaçla bu havzalara ait akım verilerinin küresel iklim değişiklikleriyle olan ilişkisinin incelenmesi amaçlanmıştır. Bu çalışmada NAO, SO ve AO'nun 1970-2015 yılları arasında Türkiye'nin batısında yer alan Büyük Menderes ve Gediz havzalarındaki 5 akım istasyonunda akım verilerinin hem yıllık hem de mevsimlik değişkenliği üzerindeki etkisi araştırılmıştır. Akım verileri ve atmosferik salınımlar arasındaki ilişkiyi belirleyebilmek için korelasyon analizi ve ayrık dalgacık dönüşümü yöntemleri kullanılmıştır.

\section{Materyal ve Metot}

\section{1. Çalışma Alanı}

Çalışma alanı, Türkiye'nin iki önemli akarsuyuna sahip olan Büyük Menderes ve Gediz havzalarıdır. Kütahya'daki Murat Dağından doğan Gediz nehri 275 km uzunluğundadır. Gediz nehrini besleyen Gediz havzası $18000 \mathrm{~km}^{2}$ yağış alanına sahip olup Türkiye yüzölçümünün \%2,17'sini oluşturmaktadır. Batı Anadolu'daki Dinar ilçesi sınırları içerisinden başlayan Büyük Menderes nehri havzası ise, $24976 \mathrm{~km}^{2}$ yağış alanına sahip olup Türkiye yüzölçümünün \%3,3’ünü oluşturmaktadır.

Bu çalışmada kullanılan aylık akım verileri Devlet Su İşleri tarafından sağlanmıştır (DSİ 2019). Büyük Menderes Havzası üzerindeki E07A001, E07A013 istasyonları ile Gediz Havzası üzerindeki E05A014, E05A022, E05A026 ak1m gözlem istasyonlarında (AGİ), akım verileri 1970-2015 yılları arasındaki 45 yıllık dönemi kapsamaktadır. Bazı akım gözlem istasyonları, baraj menba kısmına kurulduğundan ve göl alanı içerisinde kaldığından yeterli veri uzunluğuna sahip gözlem yapılamamaktadır. Bu sebeple AGİ’lerin seçiminde, baraj gölü içerisinde kalmaması, HES etkisinde olmaması, yeterli verisinin olması gibi zamansal ve mekânsal kriterler göz önünde bulundurularak istasyon seçimi yapılmıştır. Analiz için seçilen istasyonlar ve konumları Şekil 1'de gösterilmektedir. Her bir istasyonun hangi akarsu üzerinde olduğu, yüksekliği ve akımlarına ait istatistiksel veriler sırasıyla Tablo 1'de gösterilmektedir. 
Tablo 1: Istasyon bilgileri

\begin{tabular}{|c|c|c|c|c|c|c|c|c|c|c|c|c|}
\hline \multirow[b]{2}{*}{ Akarsu } & \multirow[b]{2}{*}{ İstasyon } & \multicolumn{2}{|c|}{ Yillık } & \multicolumn{2}{|l|}{ Kış } & \multicolumn{2}{|c|}{ İlkbahar } & \multicolumn{2}{|l|}{ Yaz } & \multicolumn{2}{|c|}{ Sonbahar } & \multirow[b]{2}{*}{ 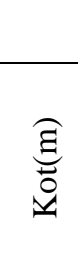 } \\
\hline & & $\begin{array}{l}\frac{\hat{m}}{m} \\
\stackrel{g}{\Xi} \\
\dot{\vec{D}}\end{array}$ & 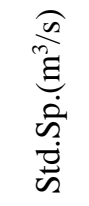 & $\begin{array}{l}\frac{\hat{m}}{\hat{m}} \\
\stackrel{\Xi}{\Xi} \\
\dot{\overrightarrow{0}}\end{array}$ & 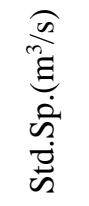 & 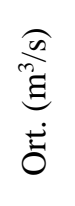 & 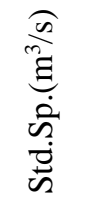 & $\begin{array}{l}\frac{\hat{D}}{m} \\
\stackrel{\Xi}{\Xi} \\
\dot{0}\end{array}$ & 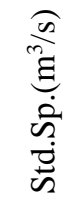 & 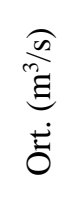 & 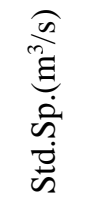 & \\
\hline & & 0,3 & 0,16 & 0,8 & 0,52 & 0,3 & 0,22 & 0,0 & 0,04 & 0,1 & 0,10 & 117 \\
\hline Gediz & E05A014 & 2,2 & 1,30 & 4,9 & 3,91 & 3,1 & 1,61 & 0,3 & 0,25 & 0,4 & 0,33 & 345 \\
\hline Gediz & E05A022 & 3,0 & 1,79 & 6,8 & 5,39 & 4,3 & 2,52 & 0,3 & 0,24 & 0,5 & 0,55 & 245 \\
\hline B.Menderes & E07A001 & 5,0 & 2,71 & 10,4 & 6,94 & 6,8 & 3,93 & 1,3 & 0,77 & 1,4 & 0,68 & 262 \\
\hline B.Menderes & E07A013 & 9,2 & 4,96 & 6,7 & 5,85 & 9,9 & 7,30 & 13,4 & 8,89 & 6,8 & 5,42 & 802 \\
\hline
\end{tabular}

Bu çalışmada, 1970-2015 yılları arasını kapsayan yıllık ve mevsimsel NAO/AO/SO verileri kullanılmıștır. Atmosferik Salınım verileri, Ulusal Okyanus ve Atmosfer İdaresi İklim Tahmin Merkezi'nden (NOAA CPC) elde edilmiştir. NAO, Azor Adaları'ndaki bir istasyon ile İzlanda'daki bir istasyon arasındaki normalleştirilmiş basınç farkı olarak tanımlanmıştır (Hurrell 1995). AO, Kuzey Yarımküre'nin arktik ve orta enlemleri arasındaki basınç dalgalanmalarına dayanan atmosferik bir bağlantıdır (Türkeş ve Erlat 2018). Bu çalışmada, yıllık, kış (aralık, ocak ve şubat), ilkbahar (mart, nisan ve mayıs), yaz (haziran, temmuz, ağustos) ve sonbahar (eylül, ekim ve kasım) dönemleri için NAO, AO, SO verileri gibi atmosferik salınımlar arasındaki bağlantılar incelenmiştir.

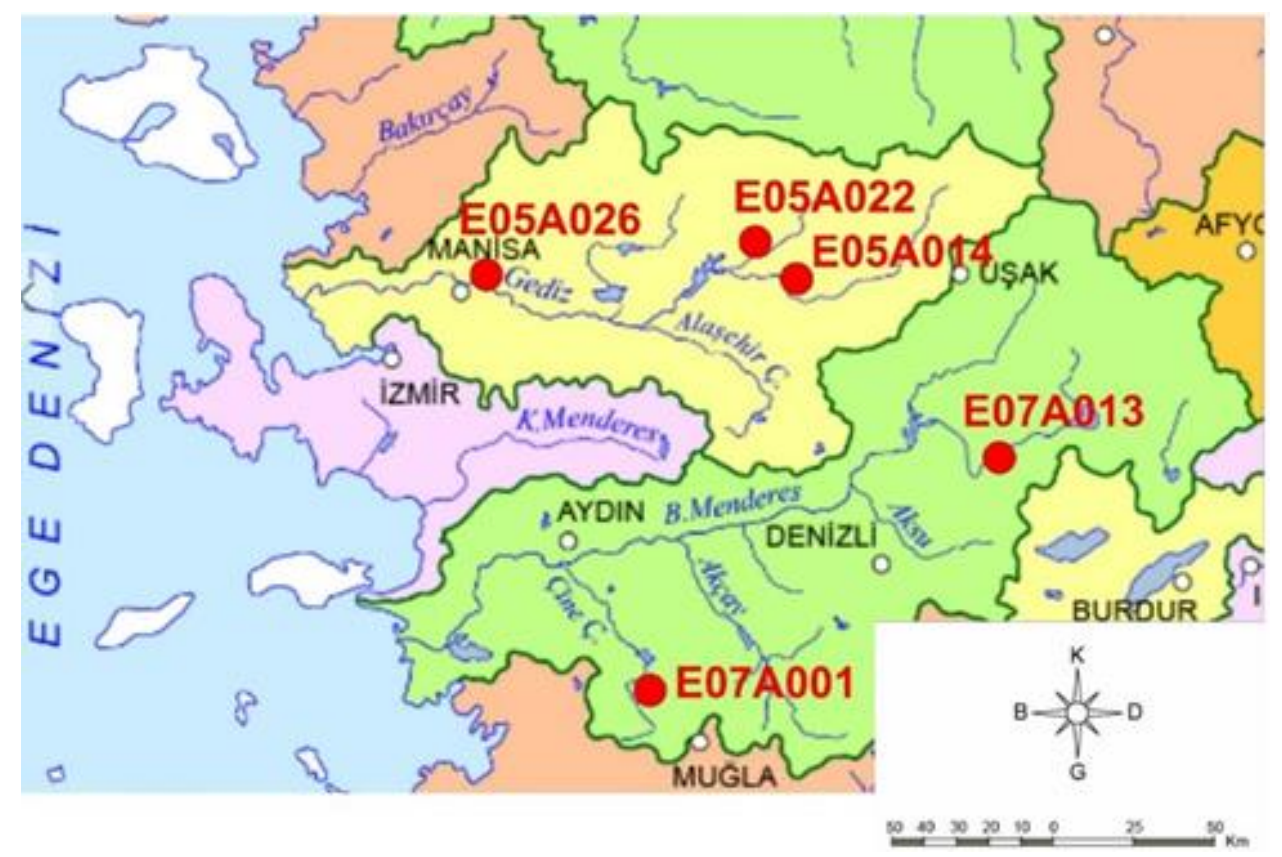

Şekil 1: Çalışmada kullanılan istasyonların dağııımı

\subsection{Pearson korelasyon katsayısı}

NAO, AO ve SO indeksleri ile mevsimsel ve yıllık akımlar arasındaki bağlantıyı ortaya koymak amacıyla, indeks değerleri ile istasyonların ortalama akım zaman serileri arasındaki Pearson korelasyon katsayıları denklem (1) kullanılarak hesaplanmıştır (Bayazıt ve Yeğen Oğuz 2005).

$r_{x, y}=\frac{\sum\left(x_{i}-\bar{x}\right)\left(y_{i}-\bar{y}\right)}{N s_{x} s_{y}}$ 
Denklem (1)'de $x_{i}$ yıllık ve mevsimlik akım verilerini, $\bar{x}$ yıllık ve mevsimlik ortalama akımı, $y_{i}$ yıllık ve mevsimlik NAO, $A O$ ve $\mathrm{SO}$ indekslerini, $\bar{y}$ yıllık ve mevsimsel ortalama $\mathrm{NAO}$, AO ve SO indekslerini, $\mathrm{N}$ veri sayısını, $\mathrm{s}_{\mathrm{x}}$ akım verilerinin standart sapmasını, $\mathrm{s}_{\mathrm{y}}$ indeks değerlerinin standart sapmasını ifade etmektedir. Bu korelasyonların istatistiksel bakımdan anlamlılığı Student t- testi kullanılarak $\alpha=0,1$ anlam seviyesinde test edilerek değerlendirilmiştir.

\subsection{Ayrık dalgacık dönüşümü}

Dalgacık dönüşümü, belirlenen zaman aralığı içine değiş̧ik periyotlardaki bir sinyalin zaman frekans temsilini sağlamaktır (Daubechies 1990). Bir dalgacık fonksiyonu $\Psi(\tau, s)$ bir ana dalgacık fonksiyonunun dönüşümü olarak yazılabilir,

$$
\psi(\tau, s)=s^{-1 / 2} \psi\left(\frac{t-\tau}{s}\right)
$$

Burada, $t$ zamanı; $s$ dalgacık ölçeğini; $\tau$ zaman adımını ifade eder (Meyer 1993). x(t) için dalgacık dönüşümü şu şekilde yazilabilir,

$$
W(\tau, s)=s^{-1 / 2} \int_{-\infty}^{+\infty} x(t) \psi^{*}\left(\frac{t-\tau}{s}\right) d t
$$

Burada, $\mathrm{W}(\tau, \mathrm{s})$ dönüşüm fonksiyonudur ve ana dalgacık fonksiyonu olarak adlandırılır. Verilerin ayrık sinyalleri, ayrık dalgacık dönüşümü ile belirlenebilir.

$$
\psi_{m, n}\left(\frac{t-\tau}{s}\right)=s_{0}^{-m / 2} \psi\left(\frac{t-n \tau_{0} s_{0}^{m}}{s_{0}^{m}}\right)
$$

Burada m ve $\mathrm{n}$ tamsayı olarak dalgacığın sırası ile ölçek ve zaman eksenindeki öteleme parametreleri; $\mathrm{s}_{0}$ sabit bir öteleme adımını ifade eder ve 1' den büyüktür; $t_{0}$ zaman eksenindeki öteleme aralığını ifade eden parametre olup 0'dan büyüktür. Burada dönüşüm adımı olan $n \tau_{0} s_{0}^{m}$, genişlemeye $\left(s_{0}^{m}\right)$ bağlıdır. Yaygın olarak s $\mathrm{s}_{0}$ ve $\tau_{0}$ sırasıyla 2 ve 1 olarak kullanılır. $\mathrm{Bu}$, frekans ekseninin örneklemesinin ikili örneklemeye karşılık gelmesi için en yaygın ve en basit tercihtir (Cannas vd. 2006). Ayrık dalgacık dönüşümü, iki ölçek ve zaman adımı çözümü ile pratik ve etkili bir çözümdür (Mallat 1989). Bir i ayrık adımına sahip xi zaman serisi için ayrık dalgacık dönüşümü aşağıdaki şekilde tanımlanabilir.

$W_{m, n}=2^{-m / 2} \sum_{i=0}^{N-1} x_{i} \psi\left(2^{-m} i-n\right)$

Burada $W m, n s=2 \mathrm{~m}$ ölçek ve $\tau=2 \mathrm{~m} \mathrm{n}$ zaman değerlerine sahip dalgacık dönüşümü katsayılarıdır. Bu çalışmada ana dalgacık olarak Daubechies(db2) dalgacık seçilmiştir. Db2, db3, db4, db5, db6, db7, db8, db9 ve db10, Daubechies dalgacık ailesinin diğer dalgacıklarıdır. Önceki çalışmaların çoğunda genellikle db2 ve db4 dalgacıkları kullanılmıştır (Cannas vd. 2006; Nourani vd. 2014).

Bu çalışmada yaklaşık bileşeni (A) ile birlikte 2, 4, 8 ve 16 yıllık periyotlara sahip D1, D2, D3 ve D4 dalgacık bileşenleri kullanılmıştır.

\section{Bulgular ve Tartışma}

\subsection{Atmosferik salınımların gözlemlenen akım verileri üzerinde etkisi}

NAO’ nun Büyük Menderes ve Gediz Akarsuları akım verileri üzerindeki etkileri, korelasyon katsayıları hesaplanarak yıllık ve mevsimsel olarak Tablo 2'de gösterilmiştir. Sonuçlar 0.1 anlamlılık düzeyinde test edilerek anlamlı korelasyonlar belirlenmiştir. İstatistiksel olarak anlamlı korelasyonlar tabloda koyu olarak yazılmıştır. Elde edilen sonuçlar incelendiğinde, yıllık akım verilerinin NAO ile tüm istasyonlarda negatif korelasyona sahip olduğu bunlardan 3 tanesinin istatistiksel önemli olduğu görülmektedir. Ayrıca NAO' nun akım verileri üzerindeki mevsimsel etkisi Şekil 2' de görülmektedir. Mevsimsel etkiler incelendiğinde, kış ve ilkbahar mevsimi için 5 istasyonun 2'sinde önemli negatif korelasyon görülmektedir. Sonbahar mevsiminde ise bir istasyonda anlamlı negatif korelasyon elde edilmiştir. Öte yandan pozitif korelasyon sadece yaz mevsiminde görülmüştür. 
Tablo 2: NAO ile gözlenen akımlar arasındaki korelasyonlar

\begin{tabular}{cccccc}
\hline İs tasyonlar & Yıllık & Kış & İlkbahar & Yaz & Sonbahar \\
\hline D05A026 & $\mathbf{- 0 , 3 0 6}$ & $-0,204$ & $-0,136$ & $-0,037$ & $\mathbf{- 0 , 4 0 3}$ \\
E05A014 & $\mathbf{- 0 , 2 9 5}$ & $\mathbf{- 0 , 3 5 2}$ & $\mathbf{- 0 , 2 6 7}$ & 0,155 & 0,058 \\
E05A022 & $\mathbf{- 0 , 2 6 3}$ & $\mathbf{- 0 , 2 9 5}$ & $\mathbf{- 0 , 2 4 0}$ & 0,138 & $-0,036$ \\
E07A001 & $-0,196$ & $-0,167$ & $-0,225$ & 0,132 & $-0,093$ \\
E07A013 & $-0,042$ & $-0,011$ & 0,021 & $\mathbf{0 , 3 6 3}$ & $-0,016$ \\
\hline
\end{tabular}

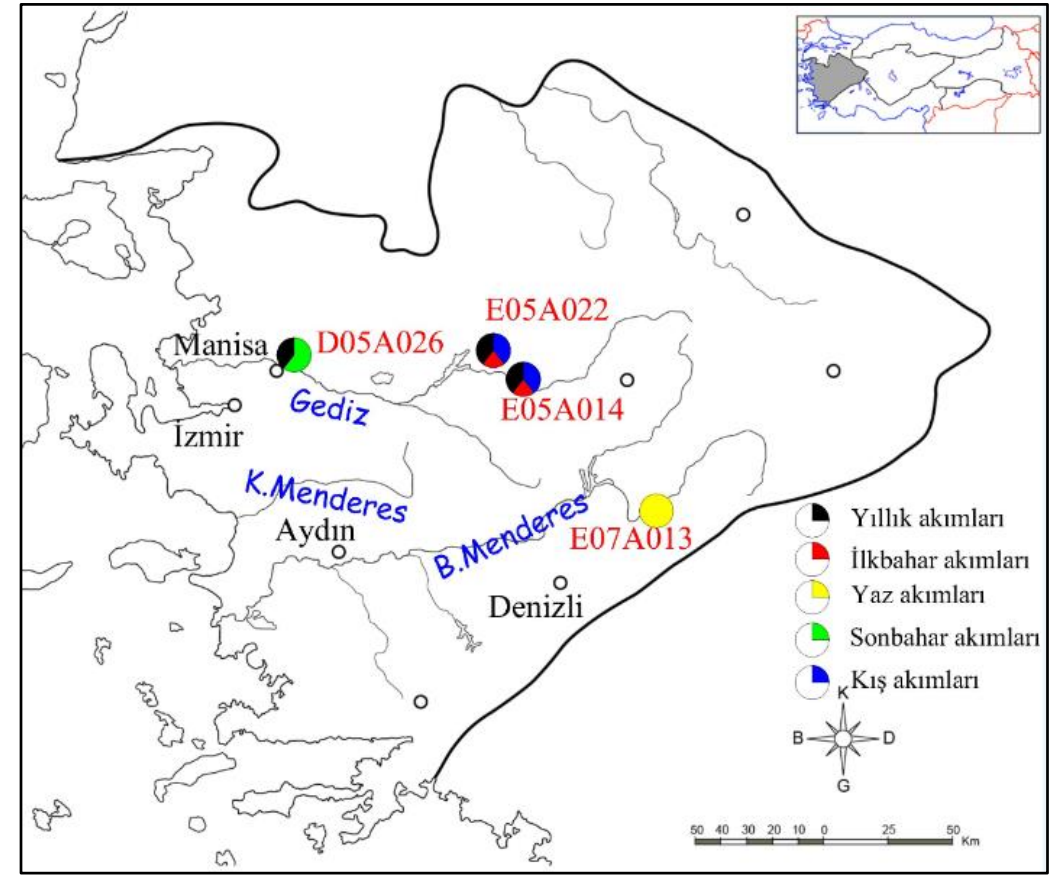

Şekil 2: Kuzey Atlantik Salınımı etkisindeki istasyonlar

AO indekslerine ilişkin korelasyon analizi sonuçları (Tablo 3 ve Şekil 3), atmosferik indeksle yıllık akım arasında açık bir negatif ilişki olduğunu göstermektedir. Yıllık akım verileri ve AO verileri arasındaki korelasyon analizlerinin neticesinde 5 istasyonun hepsinde anlamlı negatif korelasyonlar bulunmuştur. Ayrıca kış ve ilkbahar mevsiminde 4 istasyonda negatif anlamlı korelasyon bulunmuştur. AO indeksi ile istasyonların akım verileri arasında anlamlı pozitif korelasyona rastlanmamıştır. Bu sonuçlar AO indeksinin özellikle kış ve ilkbahar mevsiminde Batı Anadolu akım verileri ile negatif ilişkisi olduğu anlamına gelmektedir.

Tablo 3: AO ile gözlenen akımlar arasındaki korelasyonlar

\begin{tabular}{cccccc}
\hline İstas yonlar & Yıllık & Kış & Illkbahar & Yaz & Sonbahar \\
\hline D05A026 & $\mathbf{- 0 , 3 7}$ & $\mathbf{- 0 , 3 0}$ & $\mathbf{- 0 , 2 6}$ & $-0,04$ & $\mathbf{- 0 , 2 9}$ \\
E05A014 & $\mathbf{- 0 , 4 6}$ & $\mathbf{- 0 , 3 9}$ & $\mathbf{- 0 , 3 7}$ & 0,09 & 0,12 \\
E05A022 & $\mathbf{- 0 , 4 2}$ & $\mathbf{- 0 , 2 8}$ & $\mathbf{- 0 , 3 2}$ & 0,05 & 0,07 \\
E07A001 & $\mathbf{- 0 , 3 3}$ & $\mathbf{- 0 , 3 2}$ & $\mathbf{- 0 , 2 7}$ & 0,03 & $-0,16$ \\
E07A013 & $\mathbf{- 0 , 2 9}$ & $-0,21$ & $-0,16$ & 0,07 & $-0,17$ \\
\hline
\end{tabular}




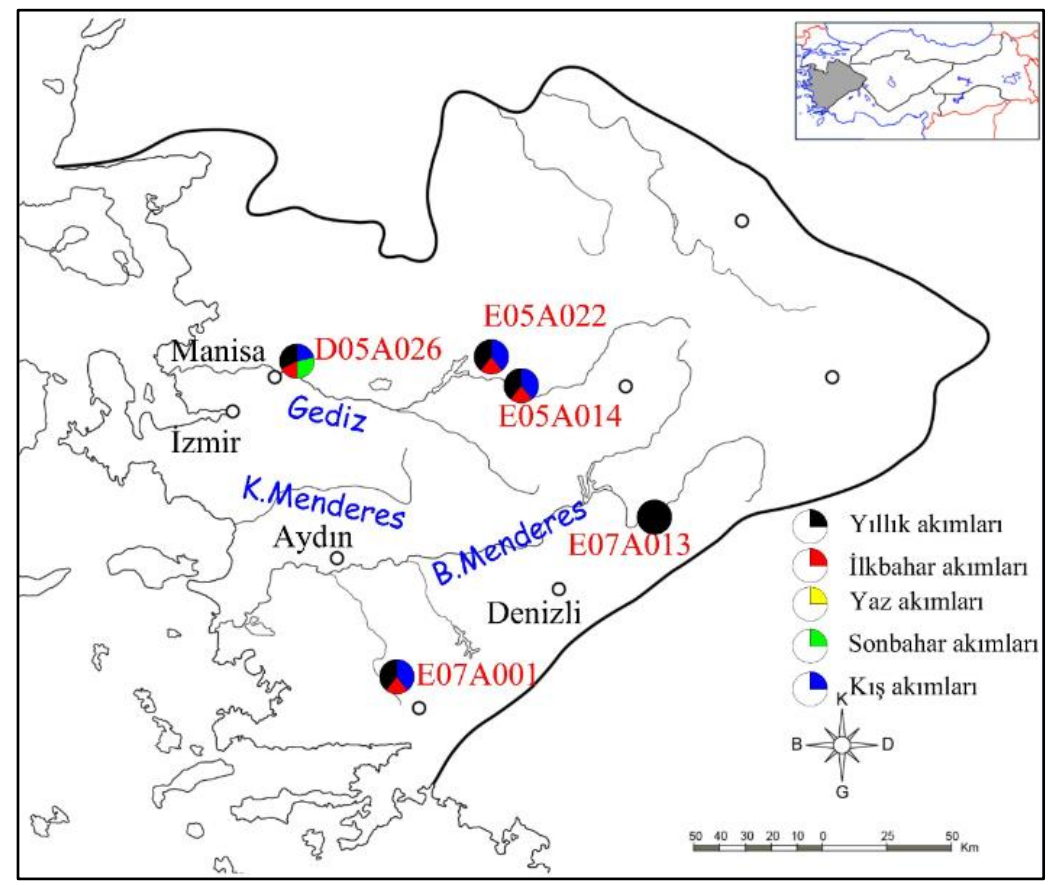

Şekil 3: AO etkisindeki istasyonlar

SO indeksinin etkileri Şekil 4 ve Tablo 4'teki yıllık ve mevsimlik olarak hesaplanan korelasyon katsayıları ile değerlendirilmiştir. Bulunan sonuçlara göre sadece D05A026 istasyonunda y1llık ve sonbahar mevsiminde önemli pozitif korelasyon bulunmuştur. Diğer istasyonlarda ise anlamlı korelasyon yoktur. SO indeksi verileri ile ilgili sonuçlara bakıldığında, Ege Bölgesi’ nde SO indeksi ile akım verileri arasında anlamlı bir ilişsi olmadığı söylenebilir.

Tablo 4: SO ile gözlenen akımlar arasındaki korelasyonlar

\begin{tabular}{cccccc}
\hline İstasyonlar & Yllık & Kış & İlkbahar & Yaz & Sonbahar \\
\hline D05A026 & $\mathbf{0 , 2 5}$ & $-0,06$ & 0,15 & 0,05 & $\mathbf{0 , 3 1}$ \\
E05A014 & 0,11 & $-0,03$ & 0,11 & 0,04 & 0,19 \\
E05A022 & 0,08 & 0,07 & 0,09 & 0,19 & 0,17 \\
E07A001 & $-0,01$ & $-0,16$ & $-0,10$ & 0,17 & 0,06 \\
E07A013 & $-0,02$ & 0,04 & $-0,04$ & 0,00 & 0,05 \\
\hline
\end{tabular}




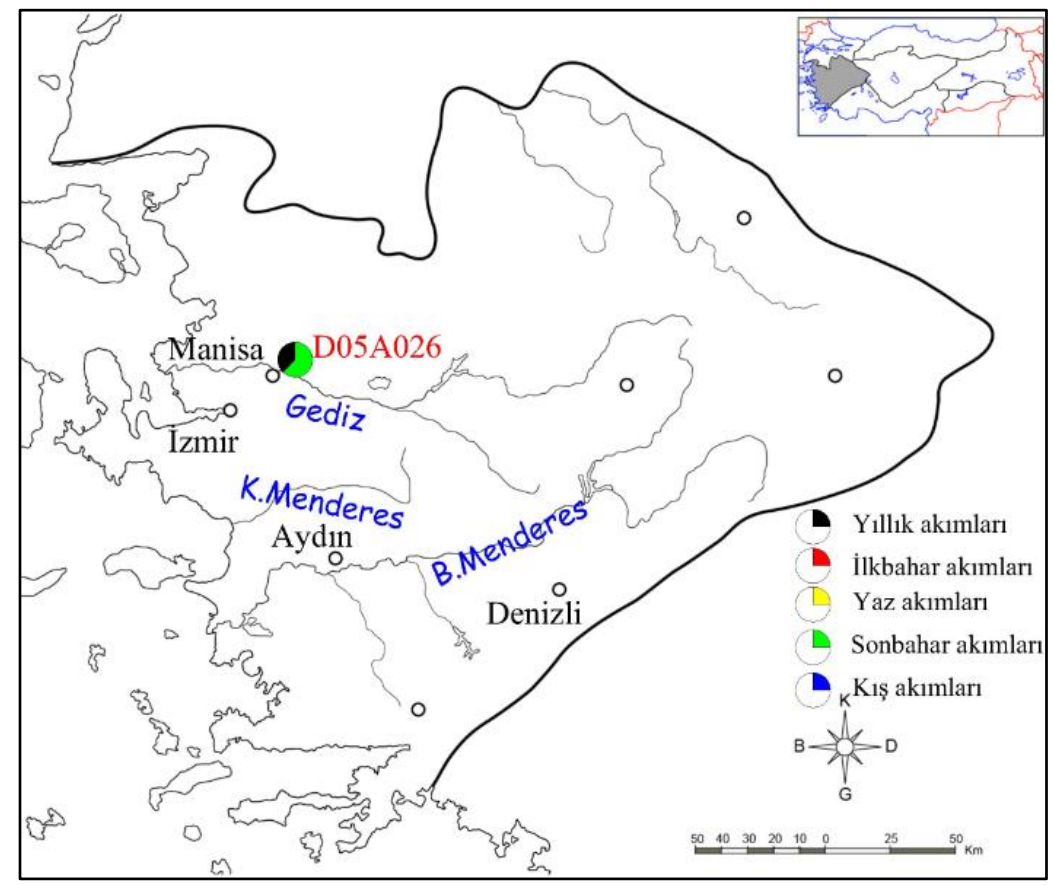

Şekil 4: SO etkisindeki istasyonlar

\subsection{Atmosferik salınımların akım verilerinin periyodik davranışları üzerindeki etkileri}

$\mathrm{Bu}$ bölümde atmosferik indisler ile gözlemlenen akım verilerinin dalgacık periyodik bileşenleri arasındaki ilişki araştırılmıştır. Bu sayede gözlenen akım verileri ile belirlenemeyen bağlantıların bulunması ve var olan korelasyonların hangi periyodiklikten kaynaklandığının bulunması amaçlanmıştır. Gözlemlenen akım verileri, ayrık dalgacık yöntemi kullanılarak yaklaşık dalgacık bileşeni (A) ve dört ayrıntı bileşenine ayrıştırılmıştır. Ayrıntı bileşenleri, verilerdeki 2 yıllık periyodikliği (D1), 4 yıllık periyodikliği (D2), 8 yıllık periyodikliği (D3) ve 16 yıllık periyodikliği (D4) temsil etmektedir. A bileşeni ise beşinci ayrıştırma seviyesindeki yaklaşık bileşenini temsil eder. Tablo 5, atmosferik salınımlar ile akım verilerinin dalgacık bileşenleri arasındaki korelasyon katsayılarını göstermektedir. Tüm korelasyonlar 0.1 önem seviyesinde test edilerek anlamlı olanlar belirlenmiştir.

Tablo 5'ten, gözlemlenen verilere göre dalgacık periyodik bileşenlerinin daha fazla korelasyon gösterdiği açıkça anlaşılmaktadır. Örneğin, NAO' nın yıllık verilerinde gözlemlenen veriler için 3 istasyonda anlamlı korelasyon varken, dalgacık periyodik verileri için farklı periyodikliklerde olmak üzere 4 istasyonda anlamlı korelasyon vardır. Öte yandan sonbahar mevsimi için dalgacık verilerin en az bir bileşeninde olmak üzere korelasyon sayıları (toplam 4 istasyon), gözlemlenen korelasyon (1 istasyon) ile karşılaştırıldığında oldukça daha belirgindir. Şekil 5, akım verilerinin dalgacık periyodiklik bileşeni ile NAO arasındaki önemli korelasyonların mevsimsel ve alansal dağılımını göstermektedir. Tablo 5 ve Şekil 5' e göre yıllık ve kış mevsimi için D2, D3 ve D4 bileşenlerinde, A ve D1 bileşenlerine göre anlamlı korelasyon daha fazla görülmüştür. Yıllıkta D2 bileşeni 4 istasyonda anlamlı negatif korelasyon gösterir. İlginçtir ki Sonbahar mevsimi için A bileşeni üç istasyonda anlamlı pozitif korelasyona sahiptir. Yaz mevsiminde ise A bileşeni iki istasyonda pozitif anlamlı korelasyon göstermektedir. 
Tablo 5: Akımların dalgacık bileşenleri ile NAO, AO ve SO indeksleri arasındaki korelasyonlar

\begin{tabular}{|c|c|c|c|c|c|c|c|c|c|c|c|c|c|c|c|c|}
\hline \multirow{2}{*}{ İS TS YN. } & \multicolumn{6}{|c|}{ NAO } & \multicolumn{5}{|c|}{ AO } & \multicolumn{5}{|c|}{ SO } \\
\hline & & YIL. & KIŞ & İLK. & YAZ & SON. & YIL. & KIŞ & İLK. & YAZ & SON & YIL. & KIŞ & İLK. & YAZ & SON. \\
\hline \multirow{5}{*}{ D05A026 } & D1 & $-0,10$ & $-0,12$ & $-0,08$ & $-0,04$ & $-0,36$ & $-0,14$ & $-0,16$ & $-0,14$ & $-0,08$ & $-0,25$ & 0,21 & $-0,15$ & 0,22 & $-0,07$ & $\underline{\mathbf{0 , 3 4}}$ \\
\hline & D2 & $-0,25$ & $-0,13$ & $-0,15$ & 0,16 & $-0,15$ & $-0,26$ & $-0,18$ & $-0,30$ & 0,17 & $-0,03$ & 0,06 & $-0,12$ & $-0,03$ & 0,17 & 0,11 \\
\hline & D3 & $-0,29$ & $-0,11$ & $-0,17$ & $-0,09$ & $-0,14$ & $\mid-0,28$ & $-0,16$ & $-0,16$ & $-0,03$ & $-0,18$ & $\underline{0,27}$ & 0,13 & 0,13 & 0,15 & 0,23 \\
\hline & D4 & $-0,16$ & $-0,09$ & 0,06 & $-0,23$ & $-0,19$ & $-0,34$ & $-0,26$ & 0,01 & $-0,21$ & $-0,27$ & $-0,03$ & 0,03 & $-0,02$ & $-0,03$ & $-0,03$ \\
\hline & A & $-0,32$ & $-0,21$ & 0,23 & $\underline{0,28}$ & $-0,17$ & $-0,16$ & $-0,20$ & $-0,03$ & $\underline{0,26}$ & $-0,09$ & $\underline{0,29}$ & $\underline{0,26}$ & $-0,37$ & $-0,17$ & $-0,22$ \\
\hline \multirow{5}{*}{ E05A014 } & D1 & $-0,10$ & $-0,03$ & $-0,05$ & 0,18 & $-0,03$ & $-0,13$ & $-0,05$ & $-0,19$ & $\underline{0,25}$ & $\underline{0,24}$ & 0,04 & 0,05 & 0,00 & 0,09 & 0,18 \\
\hline & D2 & $-0,31$ & $-0,36$ & $-0,15$ & 0,04 & $-0,11$ & $\mid-0,28$ & $-0,36$ & $-0,27$ & 0,01 & $-0,02$ & 0,18 & $-0,13$ & 0,15 & $-0,09$ & 0,16 \\
\hline & D3 & $-0,31$ & $-0,25$ & $-0,22$ & 0,07 & $-0,06$ & $\mid-0,40$ & $-0,30$ & $-0,24$ & 0,14 & $-0,09$ & 0,02 & 0,00 & 0,03 & $-0,12$ & 0,11 \\
\hline & D4 & $-0,26$ & $-0,25$ & $-0,32$ & 0,02 & 0,05 & $-0,45$ & $-0,33$ & $-0,32$ & 0,00 & $-0,19$ & $-0,03$ & 0,00 & $-0,05$ & 0,00 & $-0,06$ \\
\hline & A & 0,05 & $-0,19$ & $-0,16$ & 0,08 & $\underline{0,26}$ & $-0,12$ & $-0,15$ & $-0,06$ & $-0,12$ & 0,09 & 0,08 & $-0,03$ & 0,26 & 0,15 & 0,03 \\
\hline \multirow{5}{*}{ E05A022 } & D1 & $-0,01$ & 0,07 & $-0,03$ & 0,19 & $-0,16$ & 0,00 & 0,10 & $-0,07$ & 0,19 & 0,16 & 0,02 & 0,17 & 0,08 & $\underline{\mathbf{0 , 3 8}}$ & $\underline{0,24}$ \\
\hline & D2 & $-0,30$ & $-0,37$ & $-0,16$ & $-0,10$ & $-0,07$ & $-0,41$ & $-0,40$ & $-0,41$ & $-0,18$ & 0,06 & 0,10 & $-0,17$ & 0,05 & $-0,03$ & 0,03 \\
\hline & D3 & $-0,42$ & $-0,35$ & $-0,29$ & 0,12 & $-0,12$ & $-0,47$ & $-0,32$ & $-0,32$ & 0,20 & $-0,11$ & 0,11 & 0,13 & 0,00 & $-0,15$ & $-0,01$ \\
\hline & D4 & $-0,26$ & $-0,25$ & $-0,34$ & 0,13 & 0,02 & $-0,43$ & $-0,31$ & $-0,31$ & 0,15 & $-0,21$ & $-0,03$ & 0,00 & $-0,06$ & 0,04 & $-0,05$ \\
\hline & A & 0,05 & $-0,18$ & $-0,21$ & 0,06 & $\underline{0,25}$ & $-0,12$ & $-0,14$ & $-0,07$ & $-0,13$ & 0,09 & 0,08 & $-0,06$ & $\mathbf{0 , 3 1}$ & 0,16 & 0,06 \\
\hline \multirow{5}{*}{ E07A001 } & D1 & $-0,13$ & 0,01 & $-0,16$ & 0,04 & $-0,08$ & $-0,08$ & $-0,06$ & $-0,19$ & 0,15 & $-0,07$ & 0,07 & $-0,17$ & $-0,01$ & $\underline{0,28}$ & 0,12 \\
\hline & D2 & $-0,11$ & $-0,13$ & $-0,04$ & $-0,04$ & $-0,24$ & $-0,11$ & $-0,13$ & $-0,09$ & $-0,11$ & $-0,15$ & 0,02 & $-0,10$ & $-0,16$ & 0,13 & 0,07 \\
\hline & D3 & 0,03 & 0,07 & $-0,14$ & 0,10 & $-0,18$ & $-0,18$ & $-0,17$ & $-0,20$ & 0,09 & $-0,17$ & $-0,29$ & $-0,23$ & $-0,15$ & $-0,11$ & $-0,15$ \\
\hline & D4 & $-0,22$ & $-0,19$ & $-0,20$ & 0,12 & $-0,03$ & $-0,42$ & $-0,33$ & $-0,23$ & 0,02 & $-0,17$ & $-0,03$ & $-0,01$ & $-0,04$ & $-0,02$ & $-0,02$ \\
\hline & A & $-0,09$ & $-0,24$ & $-0,17$ & 0,14 & $\underline{0,24}$ & $-0,16$ & $-0,21$ & $-0,06$ & $-0,08$ & 0,09 & 0,21 & 0,13 & $\underline{0,28}$ & 0,13 & 0,09 \\
\hline \multirow{5}{*}{ E07A013 } & D1 & 0,02 & 0,13 & $\underline{0,24}$ & 0,09 & $-0,22$ & $-0,08$ & 0,06 & 0,00 & 0,01 & $-0,23$ & $-0,05$ & $-0,01$ & $-0,02$ & $-0,05$ & $-0,05$ \\
\hline & D2 & $-0,26$ & $-0,09$ & $-0,10$ & 0,07 & $-0,01$ & $-0,23$ & $-0,15$ & $-0,17$ & $-0,08$ & $-0,08$ & 0,09 & 0,03 & 0,02 & $-0,04$ & 0,05 \\
\hline & D3 & $-0,04$ & 0,07 & $-0,08$ & 0,16 & $-0,06$ & $-0,21$ & $-0,16$ & $-0,12$ & 0,01 & $-0,16$ & $-0,12$ & $-0,11$ & $-0,09$ & $-0,05$ & $-0,01$ \\
\hline & D4 & $-0,08$ & 0,06 & $-0,17$ & $\underline{\mathbf{0 , 3 8}}$ & $-0,05$ & $\mid-0,33$ & $-0,18$ & $-0,21$ & 0,11 & $-0,18$ & $-0,03$ & 0,02 & $-0,10$ & $-0,02$ & 0,06 \\
\hline & A & 0,10 & $-0,22$ & $-0,12$ & $\underline{0,31}$ & 0,23 & $-0,09$ & $-0,21$ & $-0,06$ & 0,08 & 0,09 & 0,04 & 0,20 & 0,22 & 0,04 & 0,10 \\
\hline
\end{tabular}

AO indeksi etkisi altında anlamlı korelasyona sahip dalgacık bileşenlerin istasyonlara göre dağılımı Şekil 6'da ve değerler ise Tablo 5'de gösterilmiştir. Yıllık veriler için istasyonların tamamında D2, D3 ve D4 bileşenlerinde negatif korelasyon görülmektedir. Bunlardan; D2 ve D3 bileşeninde 3 istasyonda, D4 bileşeni için ise 5 istasyonda da anlamlı negatif korelasyon vardır. Bu sonuç D4 bileşeninin daha etkin olduğunu göstermektedir. Kış mevsimi içinde benzer sonuçlar elde edilmiş olup D4 bileşeni etkindir. Sonbahar ve yaz mevsimi içinse çok anlamlı korelasyonlar bulunamamıştır. Sonuç olarak, verilerin uzun dönem periyodikliğini sunan D4 periyodik bileşeninin, AO indisi ile yüksek ilişki gösterdiği görülmektedir.

Akım verilerinin dalgacık periyodik bileşenleri ile SO indeksleri arasındaki anlamlı korelasyonları gösteren Tablo 5 ve Şekil 7'ye göre yıllık verilerde D3 bileşeninde 2 istasyonda, A bileşeninde ise bir istasyonda anlamlı korelasyon görülmektedir. Kış ve ilkbahar mevsimlerinde sadece A bileşeni anlamlı iken yaz ve sonbahar mevsimlerinde D1 bileşeni anlamlıdır. Özellikle ilkbahar mevsiminde A bileșeninin 5 istasyonun 4 tanesinde anlamlı korelasyon gösterdiği görülmektedir. Sonuçlara göre yıllık ve mevsimlik veriler için anlamlı çıan toplam 10 korelasyonun sadece 2 tanesi negatif olup diğerleri pozitiftir. SO indeksi ile akım verilerinin A bileşeni arasındaki önemli korelasyonların sayısının çok fazla, gözlemlenen akım verileri arasındaki önemli korelasyonların sayısı ise çok azdır. Sonuç olarak, dalgacık periyodik analizi, atmosferik salınım ve akım verileri arasındaki korelasyonu önemli ölçüde artırır. Burada SO indeksinin özellikle akımlardaki uzun vadeli değişimler üzerindeki etkisinin dikkate alınması gerektiği söylenebilir.

Özellikle SO indeksi ile gözlemlenen akım verileri arasında anlamlı korelasyonlara sahip istasyon sadece D05A026 iken, dalgacık periyodik akış verileri arasında 4 istasyonda anlamlı korelasyon bulunduğu görülmektedir. Sonuç olarak, dalgacık periyodik analizi, atmosferik salınım ve akım verileri arasındaki korelasyonu önemli ölçüde artırmaktadır. 


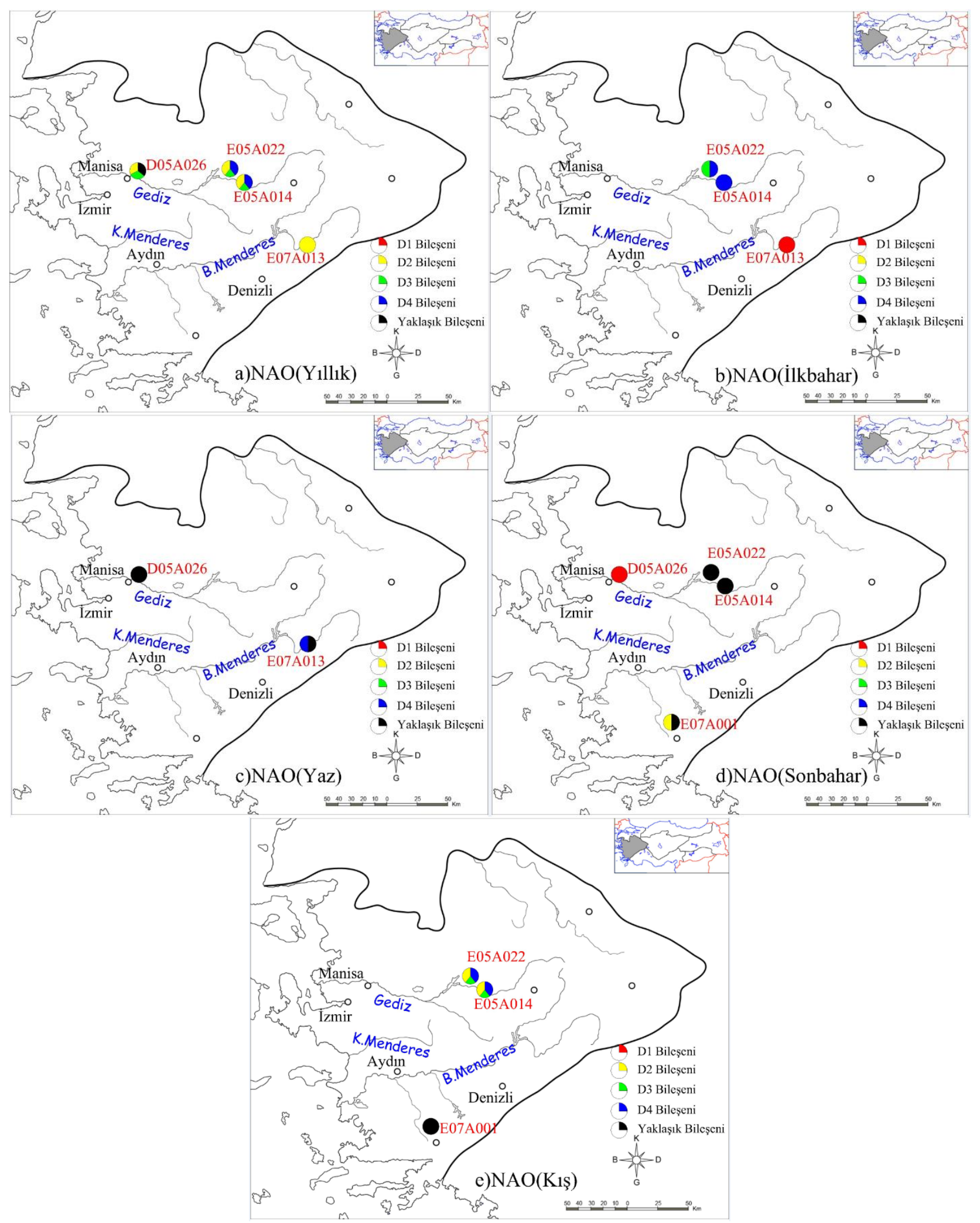

Şekil 5: Dalgacık dönüşümü sonrası NAO etkisinde olan istasyonlar a)yıllık b)ilkbahar c)yaz d)sonbahar e)kış akımları 


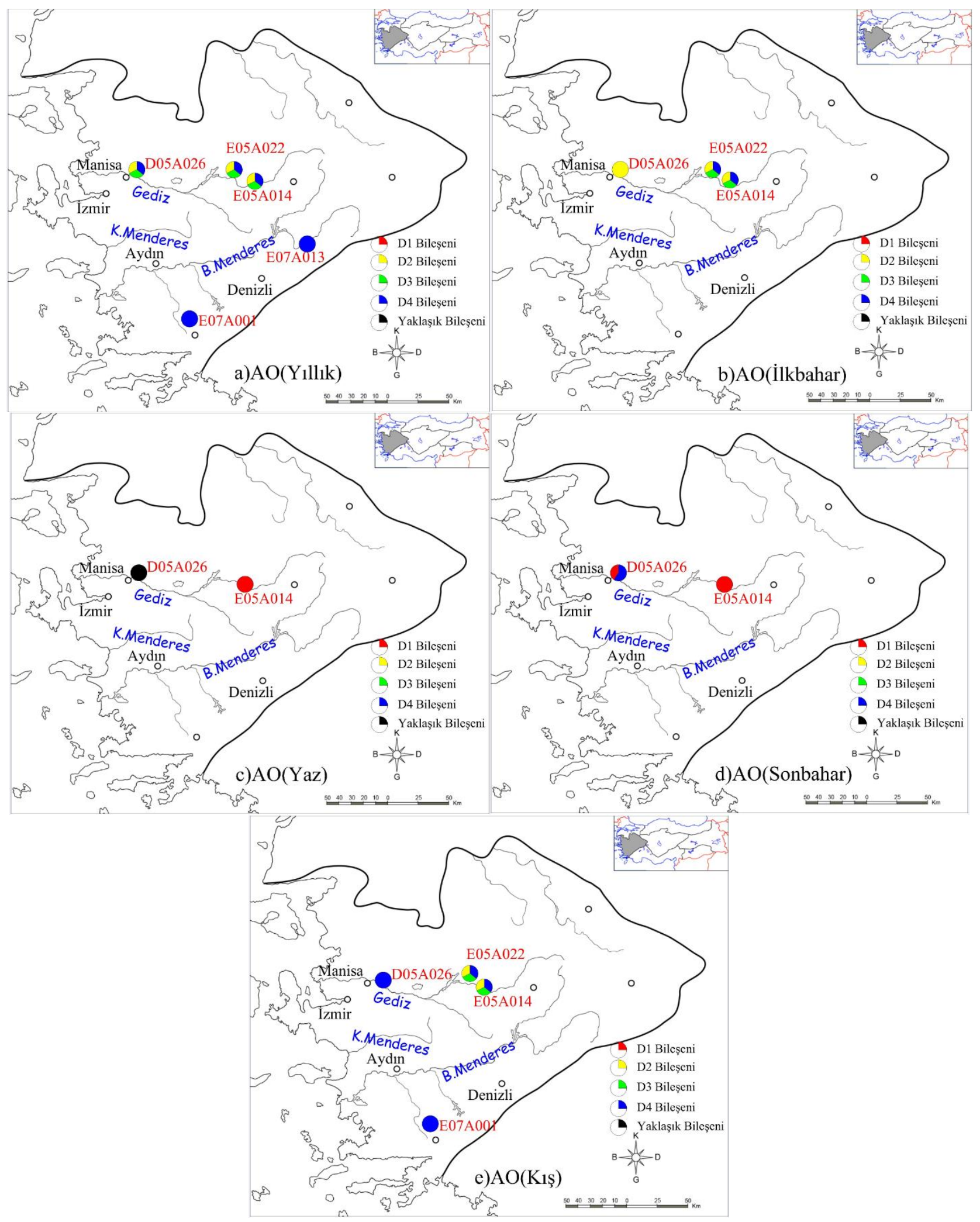

Şekil 6: Dalgacık dönüşümü sonrası AO etkisinde olan istasyonlar a)yıllık b)ilkbahar c)yaz d)sonbahar e)kış akımları 


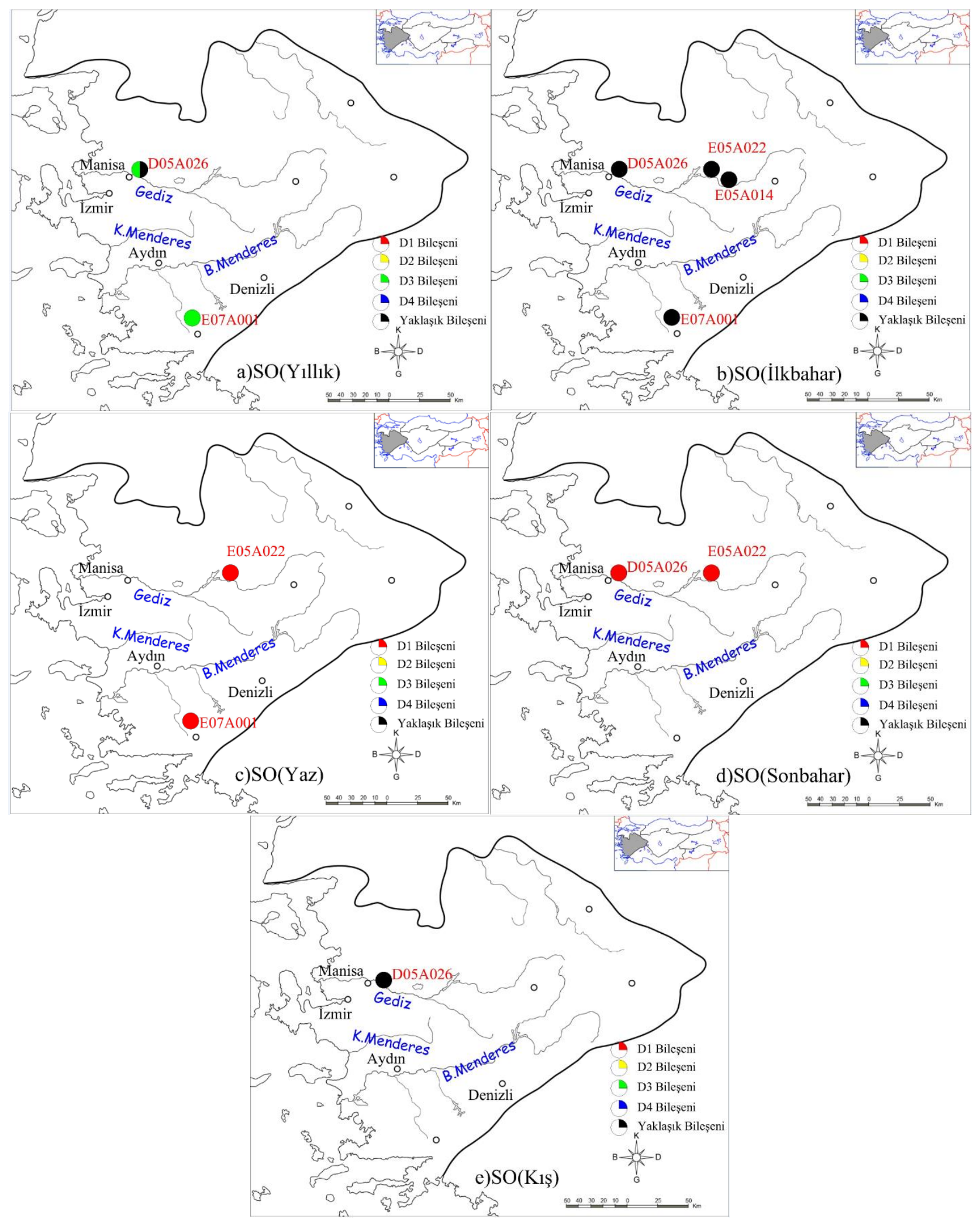

Şekil 7: Dalgacık dönüşümü sonrası SO etkisinde olan istasyonlar a)yıllık b)ilkbahar c)yaz d)sonbahar e)kış akımları

\section{Sonuç ve Tartışma}

Önceki çalışmalar göstermiştir ki özellikle kış mevsiminde negatif NAO’nun etkisi Akdeniz çevresindeki bölgelerde daha yağışı koşullara neden olmaktadır (Sezen ve Partal 2019). Önceki çalışmalar Türkiye yağış ve akış verileri ile NAO arasında bir bağlantı olduğunu göstermiştir. Genel olarak bu ilişki negatif NAO'nun aşırı değerlerinde özellikle kış ve sonbahar mevsimlerinde Türkiye genelinde yağış ve akışlarda artış, tersi olarak pozitif NAO nun aşırı değerlerinde ise 
yağış ve akışlarda kuraklık olarak gözlenmektedir (Karabörk vd. 2005; Vazifehkhah ve Kahya 2018). Bu çalışmada, küresel atmosferik salınımların, Gediz ve Büyük Menderes Havzalarında bulunan 5 akım istasyonu akım verileri üzerindeki etkisi araştırılmıştır.

1. Türkiye'nin batısında yer alan Gediz ve Büyük Menderes havzalarında yıllık akım verileri ile NAO ve AO arasında negatif ilişki bulunduğu görülmektedir. Örneğin D05A026 istasyonu için, yıllık akımla NAO arasındaki korelasyon -0,306, yıllık akımla AO arasındaki korelasyon ise -0,37 bulunmuştur. Ayrıca NAO ve AO ile, özellikle kış mevsimi akarsu akımları arasında güçlü bir negatif korelasyon bulunmuştur. Genel olarak korelasyon analizine göre NAO ve AO' nun etkisi benzer olmakla birlikte AO, ilkbaharda NAO' dan daha etkilidir. Bu çalışmada bulunan sonuçlar önceki çalışmaların sonuçlarına benzerdir. Yani yüksek pozitif NAO veya AO ile akımlardaki düşüşün özellikle kış ve ilkbahar mevsiminde beklenilebileceği görülmektedir.

2. Atmosferik indisler ve gözlenen akımlar arasında anlamlı pozitif korelasyonlar çok azdır. Yaz mevsimi için NAO ile E07A013 istasyonu akım verileri arasında ve sonbahar mevsiminde ise SO ile D05A026 istasyonu akım verileri arasında istatistiksel olarak anlamlı pozitif korelasyonlar görülmüştür.

3. Bu çalışmada, akım verilerinin periyodikliğinin atmosferik salınımlarla ilişkisi de ortaya konulmaktadır. Dalgacık periyodik bileşenleri, gözlemlenen verilere göre daha fazla korelasyon göstermektedir. Örneğin, korelasyon analizi sonucu E07A001 istasyonunda NAO etkisinde herhangi bir anlamlı korelasyon bulunmamaktadır. Ancak dalgacık analizi sonunu aynı istasyonda sonbahar mevsiminde 4 yıllık periyotta anlamlı bir ilişki saptanmıştır.

4. Sonuçlar, yıllık ve kış mevsiminde NAO ile D2 ' nin (4 yıllık periyodiklik) diğer bileşenlere göre daha fazla istasyonda negatif ilişki olduğunu göstermektedir.

5. AO indeksinin, yıllık akımların ve kış akımlarının 16 yıllık periyoda sahip D4 dalgacık bileşenleri ile önemli negatif korelasyonlara sahip olduğu görülmüştür. Buna göre, AO’nun Türkiye’nin batısındaki akımların uzun periyodlu davranışları üzerinde etkili olduğu söylenebilir.

6. SO indeksi ile gözlemlenen akarsu akım verileri arasında önemli bir korelasyon olmamakla birlikte, dalgacık analizi sonrası başta yaklaşık bileşeni (A) ile olmak üzere pek çok periyodik bileşende anlamlı ilişki olduğu görülmektedir. Özellikle ilkbahar mevsiminde A bileşeni ve SO indisi arasında ki anlamlı korelasyonlar çok fazladır. Genel olarak önceki çalışmalar SO' nun NAO ve AO ile karşılaştırıldığında daha zayıf bir ilişkiye sahip olduğunu göstermektedir. Bu sebeple bu çalışma, SO indeksinin Batı Türkiye'deki akımların uzun vadeli değişimleri üzerindeki etkisini doğrulamaktadır.

7. Dalgacık periyodik bileşenleri, bize küresel atmosferik indekslerin Batı Türkiye akımlarını temsil eden akım verileriyle olan ilişkisinin ana faktörlerini göstermektedir. Bulunan sonuçlar ana periyodik bileşeni ortaya koymaktadır.

Sonuç olarak küresel atmosferik indekslerin ( NAO ve AO gibi) aşırı pozitif değerlerinde Büyük Menderes ve Gediz akımlarında veya yağışlarında azalma beklenmektedir. Bu nedenle havzaların su yönetim planlamalarında gelecek yıllarda beklenebilecek küresel etkiler göz önüne alınarak yağış ve akışlardaki değişimler göz önüne alınmalı, gelecek çalışmalarda bu değişimlerin ve kuraklığın etkilerinin başta tarım olmak üzere bölge üzerindeki etkilerinin daha detaylı incelenmesi önerilmektedir.

\section{Kaynaklar}

Adamovski J., Prokoph A., (2014), Determining the amplitude and timing of streamflow discontinuities: A cross wavelet analysis approach, Hydrological Processes, 28(5), 2782-2793.

Adarsh S., Reddy M.J., (2015), Trend analysis of rainfall in four meteorological subdivisions of southern India using nonparametric methods and discrete wavelet transforms, International journal of Climatology, 35(6), 1107-1124.

Bayazıt M., Yeğen Oğuz E.B., (2005), Mühendisler İçin İstatistik, Birsen Yayınevi, İstanbul, 197ss.

Burt T., Howden N., (2013), North Atlantic Oscillation amplifies orographic precipitation and river flow in upland Britain, Water Resources Research, 49(6), 3504-3515.

Cannas B., Fanni A., See L., Sias G., (2006), Data processing for river flow forecasting using neural networks: Wavelet transforms and data partitioning, Physics and Chemistry of the Earth, 31, 1164-1171.

Daubechies I., (1990), The wavelet transform, time-frequency locatization and signal analysis, IEEE Transactions on Information Theory, 36(5), $961-1005$.

Dettinger M.D., Diaz H.F., (2000), Global characteristics of stream flow seasonality and variability, Journal of Hydrometeorolgy, 1(4), 289-310.

DSI, (2019), Devlet Su İşleri Genel Müdürlügü akım gözlem yıllıkları, http://www.dsi.gov.tr/faaliyetler/akim-gozlem-yilliklari (Erişim 01 Eylül 2019).

Durdu Ö. F., (2010), Effects of climate change on water resources of the Büyük Menderes River basin, western Turkey, Turkish Journal of Agriculture and Forestry, 34(4), 319-332.

Düzenli E., Tabari H., Willems P., Yilmaz MT., (2018), Decadal variability analysis of extreme precipitation in Turkey and its relationship with teleconnection patterns, Hydrological Processes, 32(23), 3513-3528

Fendekova M., Pekárová P., Fendek M., Pekár J., Škoda P., (2014), Global drivers effect in multi-annual variability of runoff, Journal of Hydrology and Hydrometeorology, 62, 169-176.

Hurrell J.W., (1995), Decadal trends in the North Atlantic Oscillation: Regional temperatures and precipitation, Science, 269, 676679. 
Iqbal M.A., Penas A., Cano-Ortiz A., Kersebaum K., Herrero L., del Río S., (2016), Analysis of recent changes in maximum and minimum temperatures in Pakistan, Atmospheric Research, 168, 234-249.

Jiang R., Gan, T.Y., Xie J., Wang N., (2014), Spatiotemporal variability of Alberta's seasonal precipitation, their teleconnection with large-scale climate anomalies and sea surface temperature, International journal of climatology, 34(9), 2899-2917.

Kahya E, Karabörk C., (2001), The analysis of El Niño and La Niña signals in streamflows of Turkey, International Journal of climatology, 21(10), 1231-1250.

Karabörk M.C., Kahya E., Karaca M., (2005), The influences of the Southern and North Atlantic, Oscillations on climatic surface variables in Turkey, Hydrological Processes, 19(6), 1185-1211.

Kutiel H., Türkes M., (2005), New Evidence for the role of the North Sea-Caspian pattern on the temperature and precipitation regimes in Continental Central, Geografiska Annaler. 87(4), 501-513.

Mallat S.G., (1989), A theory for multiresoluion signal decomposition: The wavelet representation, IEEE Transactions on Pattern Analysis and Machine Intelligence, 11(7), 674-693.

Meyer Y., (1993), Wavelets Algorithms \& Applications, Society for Industrial and Applied Mathematics, Philadelphia, 133ss.

Nalley D., Adamovski J., Khalil B., (2012), Using discrete wavelet transforms to analyze trends in streamflow and precipitation in Quebec and Ontario, Journal of Hydrology, 475, 204-228.

Nourani V., Baghanam A.H., Adamowski J., Kişi Ö., (2014), Applications of hybrid wavelet-artificial intelligence models in hydrology: a review, Journal of Hydrology, 514, 358-377.

Partal T., (2012), Wavelet analysis and multi-scale characteristics of the runoff and precipitation series of the Aegean region (Turkey), International Journal of Climatology, 32, 108-120.

Philandras C., Nastos P., Kapsomenakis I. Repapis C., (2015), Climatology of upper air temperature in the Eastern Mediterranean region, Atmospheric Research, 152, 29-42.

Pisoft P., Kalvova J., Brazdil R., (2004), Cycles and trends in the Czech temperatures series using wavelet transform, International Journal of Climatology, 24,1661-1670.

Polonsky A.B., Bardin M.Y., Voskresenskaya E.N. (2007), Statistical characteristics of cyclones and anticyclones over the Black Sea in the second half of the 20th century, Physical Oceanography,17, 348-359.

Sagarika S., Kalra A., Ahmad S., (2015), Interconnection between oceanic-atmospheric indices and variability in the US streamflow, Journal of Hydrology, 525, 724-736.

Sezen C, Partal T., (2019), The impacts of Arctic oscillation and the North Sea Caspian pattern on the temperature and precipitation regime in Turkey, Meteorology and Atmospheric Physics, 131, 1677-1696.

Tamaddun K.A., Kalra A., Ahmad S., (2016), Wavelet analyses of western US streamflow with ENSO and PDO, Journal of Water and Climate Change, 8(1), 26-39.

Türkeş M, Erlat E., (2018), Variability and trends in record air temperature events of Turkey and their associations with atmospheric oscillations and anomalous circulation patterns, International Journal of Climatology, 38(14), 5182-5204.

Vazifehkhah S, Kahya E., (2018), Hydrological drought associations with extreme phases of the North Atlantic and Arctic Oscillations over Turkey and northern Iran, International journal of Climatology, 38(12), 4459-4475.

Voskresenskaya E.N., Maslova V.N., (2011), Winter-spring cyclonic variability in the Mediterranean-Black Sea region associated with global processes in the ocean-atmosphere system, Advances in Science and Research, 6, 237-243.

Ward P.J., Kummu M., Lall U., (2016), Flood frequencies and durations and their response to El Niño Southern Oscillation: Global analysis, Journal of Hydrology, 539, 358-378.

Yılmaz C.B., Demir V., Sevimli M.F., (2020), Karadeniz Yă̆ışlarının Kuzey Atlantik Salnımı ile İlişkisi, Gazi Mühendislik Bilimleri Dergisi, 6(3), 248-254 